\title{
CRUZADA, HEREJÍA E INQUISICIÓN EN LAS TIERRAS DE LA CORONA DE ARAGÓN (SIGLOS XII-XIII)
}

\author{
POR \\ DAMIAN SMITH \\ Profesor Asociado de Historia. \\ Saint Louis University, USA
}

RESUMEN: Este estudio explora tres asuntos conectados con el tema general de la heterodoxia en el siglo XIII: la Cruzada contra los Albigenses, el aumento de la herejía en las tierras de la Corona de Aragón y el desarrollo de la Inquisición. Nos preguntamos, primero, si las decisiones tomadas por Jaime I fueron la consecuencia necesaria de la derrota en la batalla de Muret para evitar un conflicto directo con el Papado y Francia. Segundo, examinamos dónde estuvo presente y dónde ausente la herejía en las tierras de la Corona de Aragón. Tercero, sugerimos las razones por las qué la Inquisición adoptó una forma distintiva en las tierras catalano-aragonesas.

PALABRAS CLAVES: Cruzadas; herejía; Inquisición; Corona de Aragón.

\section{CRUSADE, HERESY AND INQUISITION IN THE LANDS OF THE CROWN OF ARAGON (12TH-13TH CENTURIES)}

ABSTRACT: This study explores three interconnected subjects concerning the general theme of heterodoxy in the Thirteenth Century: the Albigensian Crusade; the increase of heresy in the lands of the Crown of Aragón, and the development of the Inquisition. Firstly, we ask if the decisions taken by James I were the necessary consequence of the defeat of the battle of Muret in order to avoid a direct conflict with the papacy and France. Second, we examine where heresy as present and absent in the lands of the Crown. Third, we suggest reasons why the inquisition took a distinctive form in the lands of the Crown.

KEY WORDS: Albigensian Crusade; Heresy; Inquisition; Crown of Aragon

$\begin{array}{ll}\text { Recibido/Received } & 21-01-2013 \\ \text { Aceptado/Accepted } & 27-05-2013\end{array}$

Este estudio explora tres asuntos conectados con el tema general de la heterodoxia en el siglo XIII: la Cruzada contra los Albigenses, el aumento de la herejía en las tierras de la Corona de Aragón y el desarrollo de la Inquisición en la misma zona geográfica. Nos preguntamos, primero, si las decisiones tomadas por Jaime I de Aragón fueron la consecuencia lógica y necesaria de la derrota de la 
Corona en la batalla de Muret para evitar un conflicto directo con el Papado y Francia. Segundo, examinamos dónde estuvo presente y dónde ausente la herejía en las tierras de la Corona de Aragón, desde el concilio de San Félix (c. 1167) hasta la muerte de Jaime I en 1276. Tercero, sugerimos las razones por las qué la Inquisición adoptó una forma distintiva en el ámbito catalano-aragonés. Un factor decisivo para la comprensión de estos tres temas es la influencia cambiante de la persona del rey.

En agosto de 1271, después de las muertes del conde Alfonso y la condesa Juana, cuando, por las condiciones del tratado de Meaux-París, el condado de Toulouse debía ser incorporado a la Corona de Francia, el príncipe Pedro de Aragón, bien por iniciativa propia, bien incitado por otras personas, decidió aprovechar la ocasión para tomar posesión del condado. ${ }^{1}$ Estas noticias no fueron del agrado del padre de Pedro, el rey Jaime I de Aragón, quien el 15 de octubre mandó a sus barones y a sus concejos que no ayudaran al príncipe; de hacerlo, perderían todo lo que tuvieran. ${ }^{2}$ Además, el 17 de octubre, Jaime escribió a los alcaldes y los justicias de Aragón, ordenándoles confiscar todas las posesiones de cualquiera persona que participara en la empresa de Pedro. Jaime indicó abiertamente sus razones para intervenir. Su hijo no sólo no ganaría en honor, sino que no podría llevar a buen término lo que se había propuesto. ${ }^{3}$ Dado que el senescal de Carcassonne, Guillaume de Cohardon, había actuado con una rapidez similar para asegurar que Toulouse pasara a manos del rey francés Felipe III, e incluso había mandado que las condiciones del tratado de Corbeil (en el que el rey de Aragón había renunciado a sus derechos en el condado), fueran leídas en voz alta a la gente de Toulouse, ${ }^{4}$ el infante Pedro tuvo que abandonar su expedición. Con ello se esfumaba cualquier posibilidad de invertir el desastre de Muret y el proceso de 58 años consecuencia de esta derrota ${ }^{5}$.

Merece la pena para recordar que, en esos mismos años, el rey Jaime I había dictado gran parte, si no la totalidad, de su célebre autobiografía -ahora generalmente llamada el Llibre dels Fets-, escrita para instruir a otras personas sobre los hechos que había llevado a cabo con la ayuda de Dios y para servir como ejemplo a todos los otros hombres del mundo, 'de modo que deban hacer como

${ }^{1}$ Devic, C. y Vaissète, J. (eds.). 2003 [1730-45]. Histoire générale de Languedoc. 16 vols. vi. 927; viii, 887. Toulouse: Bibliothèque des introuvables; Zurita, J. 1967-86 [1562-80]. Anales de la Corona de Aragón, 8 vols: i, c. 79. Zaragoza: Institución "Fernando el Católico" (CSIC).

2 Fondevilla, F. 1908. "La nobleza catalano-aragonesa capitaneada por Ferrán Sánxez de Castro" I Congrés d'història de la Corona d'Aragó, ii, 1099: "Noveritis quod Infans Petrus, filius noster, vadit nunc apud Tholosam contra prohibicionem et mandatum nostrum. Quare vobis firmiter dicimus et mandamus, sub pena omnium bonorum vestrorum que habetis in terra nostra, quatenus non sitis ausus sequi ipsum, nec donetis eidem consilio et iuvamen de militibus, equis, armis, denariis vel aliis necessariis suis ad dictum viaticum faciendum....Scire enim potestis quod si nobis videretur dictum viaticum esse ad utilitatem et honorem filii nostri quod nos iuvaremus eundem ad dictum viaticum faciendum. Set quare videremus quod illud quod incipit non poterit ducere ad effectum, ideo displicet nobis plurimum et est grave.'

I Ibidem: "Et, si aliquem, contra dictam prohibicionem nostram inveneritis venisse, statim in continenti, tam de illis qui iam iverunt quam de ipsis qui de cetero ibunt, omnis bona sua emparetis et emparata teneatis quousque a nobis aliud habeatis mandatum.'

${ }^{4}$ Dossat, Y. 1961. "Les deux serments de fidélité des consuls de Toulouse en septembre 1271". Bulletin philologique et historique 703-11; ídem, 1966. Saisimentum Comitatus Tholosani: 70-82, n. 1-3; 87-9, n. 6. París: Bibliothèque nationale.

${ }^{5}$ Alvira Cabrer, M. 2002. El Jueves de Muret. 560-92. Barcelona: Universitat de Barcelona. Cingolani, S. 2010. Pere el Gran: Vida, Actes i Paraula. Barcelona: Editorial Base. 
hemos hecho y poner su fe en este Señor que es tan poderoso'. ${ }^{6}$ En el libro del rey, el asunto de las relaciones con Francia es notable por su ausencia. Las conquistas del rey en Mallorca, Valencia y Murcia están en el texto, porque demostraban la gloria que Jaime había recibido de Dios; los asuntos de Urgel y Navarra, porque Jaime anticipó que serían problemas de los que sus sucesores tendrían que ocuparse; la desgraciada cruzada a la Tierra Santa, porque el rey tuvo que justificar su fracaso y defender su honor contra los rumores de que había adelantado su regreso porque no podía vivir sin su amante, Berenguera Alonso. ${ }^{7}$ Pero, en opinión de Jaime, ningún honor había o podía ser conseguido en Languedoc. Allí, desde los primeros momentos de su vida, la Corona de Aragón había fracasado estrepitosamente en todas sus empresas.

En Muret, el 12 de septiembre de 1213 -como el testigo Raimundo VII de Toulouse le recordaría más tarde al cronista Puylaurens- los caballeros de Montfort, líder militar de la Cruzada contra los Albigenses, habían atacado a Pedro II, padre de Jaime I, con tal fuerza que el choque sonó como si una gran cantidad de hachas talara un bosque. ${ }^{8}$ La muerte del rey Pedro II fue imprevista, traumática. En enero de ese año, Pedro II había obtenido el control de Languedoc cuando, para frenar las conquistas de Montfort y las decisiones de los prelados del concilio de Lavaur, la alta nobleza de la región colocó sus posesiones bajo el poder y la autoridad del rey de Aragón. ${ }^{9}$ En Muret, con la misma rapidez, todo se perdió. Y aunque Jaime, durante su largo reinado, daría su apoyo tácito a la revuelta de Raimon Trencavel y a la coalición internacional que se formó contra los Capetos en 1241-2, y aunque siempre los hijos descontentos del Midi encontraron un sitio en su mesa, nunca estuvo dispuesto a luchar por el Languedoc. ${ }^{10} \mathrm{Ni}$ siquiera estuvo dispuesto a luchar por los intereses de la Corona de Aragón en Provenza, cuando Carlos de Anjou ganó el condado gracias a su matrimonio con Beatriz, en enero de 1246. ${ }^{11}$ Verdaderamente, sólo por Montpellier -su ciudad natal, la ciudad de su

\footnotetext{
${ }^{6}$ Bruguera, J. (ed.). 1991. Jaume I. Llibre dels Fets, 2 vols: i, c. 1. Barcelona: Editorial Barcino.

${ }^{7}$ Sobre la construcción del Llibre dels Fets, Pujol, J. M. 2008. "El programa narratiu del Llibre del Rei En Jaume", en G. Colón y T. Martínez Romero (eds.), El rei Jaume I: Fets, actes i paraules. 257-86. Barcelona: Publicacions de l'Abadia de Montserrat. Y sobre el texto en general, Cingolani, S. 2007. La Memòria dels Reis: Les quatre grans cròniques. Barcelona: Editorial Base.

${ }^{8}$ Duvernoy, J. (ed.). 1996. Guillaume de Puylaurens, Chronique 1145-1175. 88, c. 21. Toulouse: Le Pérégrinateur. Sobre la batalla, Alvira Cabrer, M. 2008. Muret 1213. La batalla decisiva de la Cruzada contra los Cátaros. Madrid: Ariel; Alvira Cabrer. 2002. Smith, D. J. 2004. Innocent III and the Crown of Aragon: the limits of papal authority. 111-42. Aldershot: Ashgate.

${ }_{9}$ Mansilla, D. (ed.) 1955. La documentación pontificia hasta Inocencio III (965-1216). 465-7, n. 461-3. Roma: Instituto Español de Estudios Eclesiásticos. Alvira Cabrer, M., Macé, L. y Smith, D.J. 2009. "Le temps de la Grande Couronne d'Aragon du roi Pierre le Catholique. À propos de deux documents relatifs à l'abbaye de Poblet (février et septembre 1213)". Annales du Midi 265: 5-22; Benito i Monclús, P. 2009. "L'expansió territorial ultrapirinenca de Barcelona i de la Corona d'Aragó: guerra, política i diplomàcia (1067-1213)", en Ferrer i Mallol, M.T. y Riu i Riu, M. (dirs.), Tractats $i$ negociacions diplomàtiques de Catalunya i de la Corona catalanoaragonesa a l'edat mitjana. Vol. I.1: Tractats i negociacions diplomàtiques amb Occitània, Franc a $i$ els estats italians, 1067-1213. 13-150. Barcelona, Institut d'Estudis Catalans (Memòries de la Secció Històrico-Arqueològica, 83).

${ }^{10}$ Véase, Smith, D. J. 2010. Crusade, Heresy and Inquisition in the Lands of the Crown of Aragon (c. 1167-1276). 13-72. Leiden: Brill Academic Press.

${ }^{11}$ Robert Ignatius Burns. 1987-1988. 'The Loss of Provence. King Jaime's raid to kidnap its heiress (1245): Documenting a legend', Congrés d'història de la Corona d'Aragó 12, iii, 195-231.
} 
querida madre, María- estuvo dispuesto a interrumpir el primer asedio de Játiva en 1239 y a negociar en el tratado de Corbeil de $1258 .^{12}$

¿Por qué? Porque una confederación catalano-aragonesa-occitana habría tenido todos los problemas del "imperio mediterráneo catalán" descrito por Hillgarth, pero muy pocas de las oportunidades que la victoria de Las Navas y la desintegración del poder de los almohades ofrecieron a los españoles cristianos en el sur y el este de la Península. ${ }^{13}$ Militarmente, las fuerzas que emprendieron las conquistas de Mallorca y de Valencia eran pequeñas. ${ }^{14}$ Pero ese número escaso de caballeros habría parecido aún más pequeño si se hubiera enfrentado a las fuerzas combinadas de Luis IX, Carlos de Anjou y Alfonso de Poitiers. Financieramente, es cierto que las rentas de la Corona de Aragón eran exiguas, especialmente durante los últimos años del reinado de Pedro II y la minoría de Jaime I, pero parecen menos escasas comparadas con las finanzas de los segundos taifas andalusíes que con la administración construida por Felipe Augusto y sostenida y desarrollada con tanta capacidad por su nieto Luis IX. ${ }^{15}$ Políticamente, en las conquistas de Mallorca, Valencia y Murcia Jaime tenía un número significativo de buenos aliados entre la nobleza (aunque, probablemente un número casi igual de aliados a regañadientes). ${ }^{16}$ Pero en el sur de Francia, incluso su primo Ramón Berenguer $\mathrm{V}$, junto al cual creció durante parte de su infancia, tendió a adoptar una política independiente, en especial en la lucha contra el conde de Toulouse, rompiendo así con una prolongada alianza entre Toulouse y la Corona de Aragón. ${ }^{17}$ Ideológicamente, mientras que en las cruzadas en el sur y en el Mediterráneo Jaime estaba luchando contra los enemigos de la fe cristiana -y por eso fue apoyado por cuantos privilegios papales fueran necesarios, especialmente de los papas Gregorio IX e Inocencio IV, en el norte habría estado luchando contra otros cristianos, lo que le habría llevado, sin duda, a incurrir en la ira del Papado. ${ }^{18}$

12 Bruguera, J. 1991: ii, c. 295. Engels, O. 1962. "Der Vertrag von Corbeil (1258)". Gesammelte Aufsätze zur Kulturgeschichte Spaniens 19: 114-46.

${ }^{13}$ Hillgarth, J. 1975. The Problem of a Catalan Mediterranean Empire, 1229-1327. Londres: Longman.

14 Sobre las cruzadas de Mallorca y Valencia, Torró, J. 2008. "Jaume I i la formació del Regne de València. Una perspectiva general", y Cateura, P. "Jaume I: conquesta i organització del regne de Mallorca” en G. Colón y T. Martínez Romero (eds.), El rei Jaume I: Fets, actes i paraules 13-51. Barcelona: Publicacions de l'Abadia de Montserrat.

15 Sobre las finanzas, Bisson, T. 1984. Fiscal Accounts of Catalonia under the Early CountKings (1151-1213), 2 vols. Berkeley: University of California Press; Bisson, T. 1989. "The Finances of the Young King Jaime I (1213-28)" en Idem, Medieval France and her Pyrenean Neighbours: Studies in Early Institutional History: 351-92. Londres: Hambledon Press. Sobre el gobierno de Felipe Augusto, Baldwin, J. 1992. The Government of Philip Augustus. Berkeley: University of California Press.

${ }^{16}$ Sobre la nobleza, Utrilla Utrilla, J. 2009. "La nobleza aragonesa y el Estado en el siglo XIII: composición, jerarquización y comportamientos políticos", y Claramunt, S. 2009. 'La nobleza en Cataluña durante el reinado de Jaime l', en E. Sarasa (ed.), La sociedad en Aragón y Cataluña en el reinado de Jaime I (1213-1276). 199-229. Zaragoza: CSIC.

17 Sobre Raymond Bérenguer V, Pecout, T. 2004. Raymond Bérenguer V: L'invention de la Provence. París: Perrin.

${ }^{18}$ Domínguez Sánchez, S. (ed.). 2004. Documentos de Gregorio IX (1227-1241) referentes a España: n. 90, 108, 150, 157, 160, 210, 222, 311-2, 623-4, 626-9, 631, 636-7, 639, 641, 669, 735. León: Universidad de León; Burns, R. I. 1988. “A Lost Crusade: Unpublished Bulls of Innocent IV on al-Azraq's revolt in Thirteenth century Spain". Catholic Historical Review 74: 440-9; Quintano Prieto, A. (ed.). 1987. La documentación pontificia de Inocencio IV (1243-54): n. 557-9, 616, 619620. Roma: Instituto español de historia eclesiástica. 
Ya a la tierna edad de nueve años, Jaime I había conocido la realidad de esa ira en toda su crudeza, cuando Honorio III amenazó sus reinos con una invasión si se emprendía una guerra contra los cruzados antialbigenses. ${ }^{19}$ Quedó todavía más claro en 1245, cuando Inocencio IV -quien inicialmente se había mostrado comprensivo ante las quejas de Jaime (cuando éste vio bloqueado su intento de traer a Beatriz de Provenza a Aragón)- cambió de opinión después de su célebre entrevista con Luis IX y advirtió a Jaime de los peligros de oponerse a la unión entre Beatriz y Carlos de Anjou. ${ }^{20}$

Por mucho que los trovadores lamentaran que Jaime no interviniera (y lo lamentaron hondamente), ${ }^{21}$ sus decisiones, dadas las limitaciones internas y externas, fueron razonables. En 1258, en Corbeil, Jaime escapó al vasallaje teórico del rey de Francia que afectaba a muchas de sus tierras y protegió la lucrativa ciudad de Montpellier. ${ }^{22}$ En este período, quizás el menos estudiado del reinado, Jaime se concentró en la consolidación de sus reinos. Una parte de ese proceso de consolidación significó el creciente interés del rey en la persecución de la depravación herética, el crimen asociado con los señores del Midi y por el que éstos habían sufrido tanto.

Trazar los primeros años en Cataluña de la herejía ahora normalmente llamada catarismo no es muy fácil. ${ }^{23}$ Aunque el cardenal Jacinto Bobone (más tarde Celestino III [1191-1198]) legisló contra la herejía en el concilio de Lérida de 1155, no está claro que apuntara a un grupo específico de herejes. ${ }^{24}$ El texto del llamado 'concilio' de Saint-Félix, posiblemente de 1167, alude a un 'Bernardus Catalanus' que entró al concilio como el representante más importante de la Iglesia de Carcassonne. También alude probablemente a los límites de las diócesis heréticas de Tortosa y Lérida. ${ }^{25}$ Pero es posible que este texto sea una falsificación, e incluso si no lo es, es difícil saber si alguien con el nombre 'Catalanus' habría vivido en Cataluña, y puede también que las referencias a Tortosa y Lérida sean una mala interpretación del documento original. ${ }^{26}$ El cardenal Enrique de Albano, un personaje muy importante en la lucha contra herejía, estaba en Huesca y Gerona

${ }^{19}$ Mansilla, D. (ed.) 1965. La documentación pontificia de Honorio III (1216-1227): 86-7, n. 106. Roma. Instituto Español de Estudios Eclesiásticos.

${ }^{20}$ Quintano Prieto.1987: 283, n. 252.

${ }^{21}$ Nicolau y d'Olwer, L. 1908. "Jaume I y los trovadors provensals". I Congrés d'història de la Corona d'Aragó, i: 389-407; Alvira. 2002: 546-53.

${ }_{22}$ Huici Miranda, A. y Cabanes Pecourt, M. (eds.). 1976-82. Documentos de Jaime $I$ de Aragón. 5 vols: iv, 109-13, n. 1018-19. Valencia-Zaragoza: Anúbar; Teulet, A. (ed.), 1863-1909. Layettes du trésor des Chartes, 5 vols: ii, 406-7, no. 4412. París: Plon.

${ }^{23}$ Sobre esta cuestión, Ventura, J. 1963. Els heretges catalans. Barcelona: Selecta; Adroer, A. y Catalá, P. 1986. Càtars i Catarisme a Catalunya. Barcelona: Rafael Dalmau; Baraut, C. 19941995. "La presencia i la repressió del catarisme al bisbat d'Urgell (segles XII-XIII)". Urgellia 12: 487524; Ídem. 1996-1997. "Els inicis de la inquisició a Catalunya i les seves actuacions al bisbat d'Urgell (segles XII-XIII)". Urgellia 13: 407-438; Grau Torras, S. 2012. Cátaros e Inquisición. 159-85. Madrid: Cátedra.

${ }^{24}$ Gonzalvo i Bou, G. (ed.). 1994. Les Constitucions de Pau i Treva de Catalunya: segles XIXIII: 58, n. 12. Barcelona: Generalitat de Catalunya, Departament de Justícia.

${ }^{25}$ Hamilton, B. 1978. "The Cathar Council of Saint-Félix Reconsidered". Archivum Fratrum Praedicatorum 48: 51-53.

${ }^{26}$ Véase Guinot, E. 1999. Els fundadors del regne de València, 2 vols: i, 93-110. Valencia: Climent; Zerner, M. (ed.). 2001. L’histoire du Catharisme en discussion: Le 'Concile' de Saint-Félix (1167): 14, 251. Nice: Université de Nice. 
en la primavera de 1181, aunque solamente tenemos una referencia a sus actividades solucionando disputas sobre diezmos y herencias. ${ }^{27}$

Pero podemos afirmar con seguridad que los herejes estaban presentes en Cataluña durante la década de 1190, y no es ninguna sorpresa que llegaran a través de las tierras del Alto Urgel, ni que fueran apoyados por Arnau, el vizconde de Castellbò, quien, junto al conde de Foix, dirigió ataques salvajes contra la Iglesia de Urgel en 1195-6, algunos de los cuales tuvieron como blanco el sacramento de la Eucaristía. ${ }^{28}$ En la iglesia de Sanavastre, el relicario que contenía el Corpus Domini fue destruido y su contenido dispersado en los lugares más viles, mientras que Arnau de Castellbò contemplaba la escena desde la puerta de la iglesia. ${ }^{29} \mathrm{El}$ Corpus Domini fue sacado de la iglesia de Palad y arrojado a un estercolero. ${ }^{30}$ Los Castellbò habían luchado durante mucho tiempo para arrebatar el control de los castillos y los diezmos del norte del condado de Urgel a la Iglesia y a los condes urgelitanos, y, cuando los agravios supuraron y Arnau entró en una alianza cada vez mas estrecha con el conde de Foix, que también prestaba ayuda a los herejes, los predicadores heréticos pudieron entrar en sus tierras y en las de sus vasallos. ${ }^{31}$

Es indudable que Arnau de Castellbò y su hija Ermessenda apoyaron a los herejes. Hay demasiados testigos de la Inquisición que los reconocen en las reuniones heréticas. Para cuando Arnau falleció en 1226, es bastante claro que en Castellbò existía un grupo religioso significativo con una jerarquía, unas casas, unas creencias que predicaron y un sistema de prácticas rituales parecido al conocido en Languedoc. Pèire Guilhem d'Arvigna, cuando compareció delante del Tribunal de la Inquisición de los predicadores dominicos Ferrer de Vilaroja y Durand en 1246, dio detalles de un concilio herético celebrado en Mirepoix en 1221, en la casa del prior de Mausus. El diácono Guilhabert de Castres presidió la asamblea y entre los presentes estuvieron el conde de Pallars, Roger de Comminges, Raimon d'Arvigna y Arnau de Castellbò. ${ }^{32}$ En su largo testimonio delante de Ferrer, el 12 de mayo de 1244, Arnau de Bretos, un miembro de una familia herética de Berga, declaró, entre otros asuntos, que hacía veinte años, en Castellbò, había visto a Guillem Clerc, un diácono herético, y a Ramon, su compañero, en la casa de herejes utilizaban abiertamente en la ciudad. ${ }^{33}$ Durante su predicación estuvieron presentes allí Arnau de Castellbò, señor del castrum, los caballeros Ramon de Castellarnau y su hermano Galcerán, y otro caballero, Berenguer de $\mathrm{Pi}^{34}$ Arnau de Bretos declaró que cuando Guillem y Ramon acabaron la predicación, todo el

${ }^{27}$ Durán Gudiol, A. (ed.). 1965-7. Colección diplomática de la catedral de Huesca, 2 vols: i, 350-2. Zaragoza: CSIC; Marquès, J. (ed.) 1984. Pergamins de la Mitra (891-1687), Arxiu diocesà de Girona: 17, n. 58. Gerona: Institut d'Estudis Gironins.

${ }^{28}$ Hageneder, O. y Haidacher, A. (eds.). 1964. Die Register Innocenz' III, 1. Pontifikatsjahr: n. 452. Colonia: Böhlau; c. 202-3; Guébin, P. y Lyons, E. (eds.). 1926-39. Petrum Vallium Sernaii monachi Hystoria Albigensis. 3 vols: i, c. 202. París: Champion; Baraut, C. 1992-3. "L'evolució política de la senyoria d'Andorra des dels orígens fins als Pariatges (segles IX-XIII)". Urgellia 11: 290-9, n. 1. Jiménez-Sanchez, P. 2008. Les catharismes: Modèles dissidents du christianisme médiéval (XIle-XIIle siècles). 319-22. Rennes: Presses Universitaires de Rennes.

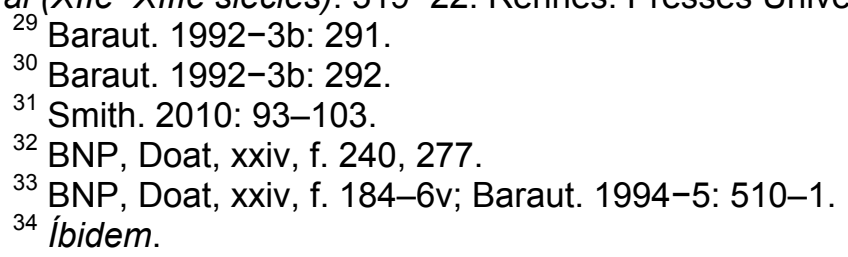


mundo los adoró. ${ }^{35}$ Además, Dyas de Deine, la viuda de Bernat de Montaut, declaró el 18 de diciembre de 1243 al inquisidor Ferrer que si Ermessenda de Castellbò no había sido una anciana (de la comunidad herética) como Esclarmonda de Foix (la hermana del conde de Foix), sí era una creyente y que adoraba a los ancianos. ${ }^{36}$ Dyas recordó que la predicación herética era habitual en Castellbò, aunque no podía recordar los nombres de los predicadores, y que había visto en la casa del caballero Arnaud de Paris a Ermessenda junto a Berenguera de Cornellana, Timbors, que era la esposa de Ramon de Josa del Cadí, y a muchos otros. Se habían arrodillado tres veces delante de los herejes, diciendo cada vez 'benedicite' y después del tercer 'benedicite' pidieron ser hechos buenos cristianos y ser llevados a una buena muerte. ${ }^{37}$ Cuando la Inquisición entró en Castellbò, en mayo de 1237, condenó a cuarenta y cinco personas como herejes o creyentes en los herejes, exhumó dieciocho cadáveres más y quemó sus huesos, condenando también a otras quince personas que ya habían huido, y todo esto en un momento en el que la Inquisición tenía que atender y determinar otros procesos. ${ }^{38}$

Incluso antes de la creación de la Inquisición, parece que el centro de las actividades de los herejes se había desplazado lejos de Castellbò. De hecho, en 1229, cuando Ramon de Bretos cayó enfermo en Berga, antes de fallecer envió a su sobrino a Castellbò para encontrar perfecti que lo consolaran, pero no pudo encontrarlos alli. ${ }^{39}$ Sin embargo, a unos cuarenta kilómetros al sureste, en Josa, no tuvo ningún problema. De hecho, en 1234, cuando Pere de Bretos murió en Berga, su familia pudo rápidamente dar con dos herejes de Josa. ${ }^{40}$ Los señores de Josa del Cadí eran parientes de los Castellbò y también habían luchado durante mucho tiempo contra la Iglesia de Urgel. Ramon de Josa el Mayor había sido excomulgado en 1201, junto a Arnau, por sus ataques contra la Iglesia. Ramon el Menor jugó durante mucho tiempo un papel importante en la recepción y el hospedaje de los herejes, y también entorpeció las maniobras de la Iglesia cuando los capturó.${ }^{41}$ Fue condenado póstumamente en 1258, en presencia del rey, y se exhumaron sus huesos. ${ }^{42}$ Gracias a él, la herejía se había difundido por esas tierras en todas direcciones. Veinte kilómetros al sudeste, en la citada Berga, la familia Bretos encabezó y estableció conexiones fuertes con Montségur, e incluso después de su captura, la Inquisición condenó a muchas personas allí en la década de $1250 .{ }^{43}$ Asimismo, en Gósol, diez kilómetros al noroeste de Berga, Maria Poca testificó en 1250 ante la Inquisición que había pocas casas que no contuvieran herejes y que haereticos'.

35 Íbidem: 'et ibi ipse testis et omnes alii praedicti finito sermone adoraverunt dictos

${ }^{36}$ BNP, Doat, xxiii, f. 71-71v.

${ }^{37}$ Ibídem.

${ }^{38}$ BNP, Doat, clxx, f. 75; Devic. 2003: viii, 1010-1.

${ }^{39}$ BNP, Doat, xxiv, f. 184-186v.

${ }^{40}$ Ibídem.

${ }^{41}$ Gascón Chopo, C. 2003. Crisis social, espiritualidad y herejía en la diócesis de Urgel (siglos XII-XIII): Los orígenes y la difusión de la herejía cátara en la antigua diócesis de Urgel: 75. Tesis Doctoral, Facultad de Geografía e Historia, Universidad Nacional de Educación a Distancia; Smith. 2010: 103-5.

${ }_{42}^{42}$ ACU, Liber Dotaliarum, ii, doc. 68, f. 71-72v; Baraut.1994-5: 516-7, n. 12.

${ }^{43}$ Cazenave, A. 1972. "Les Cathares en Catalogne et Sabarthès d'après les registres d'Inquisition: la hiérarchie Cathare en Sabarthès après Montségur". Bulletin philologique et historique: 393, n. 9; Baraut.1994-5: 497. 
los buenos hombres asistieron a mucha gente antes de morir. ${ }^{44}$ En efecto, trece personas de Gósol fueron condenadas por herejía en 1256 y enviadas a la cárcel del arzobispo de Tarragona. La tierra de Gósol pertenecía a Galceran de Pinós y, en mayo de 1256, él mismo actuó como fiador por los trece condenados ante el arzobispo Benet durante un plazo de tiempo establecido, prometiendo bajo juramento que los devolvería cuando el arzobispo lo exigiera. ${ }^{45}$

Como Ramon Joan d'Abia detalló ante la Inquisición en 1238, fue por estas tierras, y particularmente por las de Josa y Berga, por las que cruzaron los predicadores heréticos para llegar del norte a Lérida y a la región montañosa de Montsant y Prades. Aunque, desgraciadamente para nosotros, Ramon no pudo o, lo más probable, no quiso proporcionar nombres, parece que los predicadores heréticos solían ser bien recibidos en Lérida desde los años 1220, en especial entre la población inmigrante del Languedoc. ${ }^{46}$ La Inquisición inició sus pesquisas en Lérida en 1248, cuando Inocencio IV permitió que el obispo Guillem absolviera de la sentencia de excomunión a los herejes que habían vuelto espontáneamente a la unidad de la Iglesia con tal de que abjuraran de su herejía abiertamente. Las investigaciones se reanudaron en 1257, estando al frente Berenguer d'Erill y Pere d'Albalat, ayudados por los inquisidores Pierre de Tenes y Guillaume. ${ }^{47}$ El 30 de agosto de 1257, Jaime I concedió una amnistía en Lérida para los herejes que la Inquisición había descubierto y que deseaban volver a la fe católica, exigiendo un pago de 2.000 morabetini alfonsini. ${ }^{48}$

La situación era bastante diferente en las montañas. Sabemos del largo testimonio de Arnau de Bretos, en 1242, confirmando que muchas familias de la región montañosa estaban implicadas, activa y constantemente, en la protección de los herejes, que comprendían algo de las creencias de los herejes y que participaban en los ritos asociados con la herejía. ${ }^{49}$ En los primeros años sesenta, las inquisiciones fueron conducidas contra ellos por Pere de Cadireta. Los bienes de algunos fueron confiscados por el rey y otros fueron quemados. ${ }^{50} \mathrm{Sin}$ embargo, no está claro si, cuando la herejía entró en la región, casi cuarenta años antes, una religión sustituyó a otra o si la gente de las montañas era consciente de su oposición a la Iglesia o si demostraron así su hostilidad a la Iglesia. Es decir, parece que en aquel momento no se había desarrollado una gran organización eclesiástica en esas comarcas, como lo prueba el hecho de que la primera campaña de

${ }^{44}$ Pujol, P. 1984. Obra Completa. 31-2. Andorra: Editorial Andorra; Grau Torras. 2012: 361-84.

${ }^{45}$ AB, i, 61; Baraut. 1994-5: 514-5, n. 11a; Bartrina, E. 1999. Els Càtars al Berguedà: 17-8, no. 3. Bagà: Associació Medieval de Bagà.

${ }^{46}$ BNP, Doat, xxiii, f. 260-273.

47 Quintano Prieto.1987: ii, 495-6, no. 526; Vincke, J. 1941. Zur Vorgeschichte der Spanischen Inquisition: Die Inquisition in Aragon, Katalonien, Mallorca und Valencia während des 13. und 14. Jahrhunderts: 19. Bonn: Hanstein.

${ }^{48}$ Huici Miranda. 1976-82: iii, 243, no. 762.

${ }^{49}$ BNP, Doat, xxiv, f. 182-93.

${ }^{50}$ AHN, n. 1234b, f. 140v; Huici Miranda. 1976-82: iv, 321-2, 354-5, n. 1248-9, 1287-8; Gort, E. 2006. Occitans i Càtars a Montsant i muntanyes de Prades (Segles XII-XIV): 35. Albarca: Migdia; Fort i Cogul, E. 1973. Catalunya i la Inquisició: 63-4. Barcelona: Editorial Aedos; Ventura, J. 1961-2. "La Valdesía de Cataluña". Boletín de la Real Academia de Buenas Letras de Barcelona 29: 314-6. 
predicación contra la herejía fuera emprendida en 1220 por los cartujos de Escaladei. ${ }^{51}$

En las tierras de Cerdaña, Conflent y Rosellón, la herejía no parece haber tenido la misma intensidad, pero sí una presencia significativa. El inquisidor Ponç de Planella trabajó en Puigcerdà en $1242 .{ }^{52}$ Muchos peregrinos viajaban desde Cerdaña a Montségur. ${ }^{53}$ Como apuntó Wakefield, la importante familia de los Niort, representantes del gobierno catalano-aragonés, estuvo implicada profundamente en la herejía. ${ }^{54}$ En 1236, Guillem de Niort confesó que había contribuido voluntariamente a la difusión de herejía en las tierras bajo su control y fue condenado por ello a la hoguera. Es probable que escapara del castigo solamente porque su muerte habría desembocado en un conflicto grave entre otros oficiales reales y su poderosa familia. ${ }^{55} \mathrm{Su}$ primo, Bernat d'Alió, tuvo menos suerte y fue quemado en la hoguera en Perpiñán, delante de Jaime I, en $1258 .^{56}$ En 1260 , un señor notable del Conflent, Ponç de Vernet, fue condenado a muerte de forma póstuma como simpatizante de la herejía, y sus huesos fueron exhumados. ${ }^{57}$ Dos años más tarde, Pierre de Fenouillet, que había muerto en 1243, sufrió el mismo destino, aunque la significativa difusión de la herejía en Fenouillèdes ocurrió en los años posteriores a su muerte. ${ }^{58}$ También en 1243, Arnaud de Mudagons fue condenado póstumamente, en la casa de los franciscanos de Perpiñán, por adorar a los herejes con frecuencia, diciendo 'benedicite', doblando la rodilla tres veces delante de ellos, pidiendo que rezaran por él porque era un pecador e incluso recibiendo muchas veces de ellos el ósculo de la paz. ${ }^{59}$ Ramon de Malloles y su mujer fueron condenados en 1244 después de una larga campaña contra ellos del obispo de Elna, Bernat de Berga. ${ }^{60}$ Guilhem Cabiblanc, en julio de 1245, admitió que había visto a los herejes en Perpiñán, en la casa de Arnaud de Cos, y en Quéribus, en un cuarto de la casa de Beneg de Termes, entre otros lugares. Guilhem afirmó haber oído decir a los herejes que cuando el alma de un hombre parte de su cuerpo, entra en el cuerpo de un asno, buscando su salvación alli. ${ }^{61}$

En febrero de 1237, Gregorio IX mandó al arzobispo de Vienne, como legado de la sede apostólica, desarraigar la herejía en Montpellier, después de que los

${ }^{51}$ Gort. 2006: 51-3, n. 1.

52 Baraut. 1994-5: 508-10, n. 7.

${ }^{53}$ Cazenave. 1972: 392.

54 Wakefield, W. 1970. "The Family of Niort in the Albigensian Crusade and before the Inquisition". Names: Journal of the American Name Society, 18: 97-117, 286-303.

55 BNP, Doat, xxi, ff. 163v-7v; Devic. 2003: viii, 1014-5; Molinier, C. (ed.). 1880. Guilhem Pelhisso, Chronique: 25-32. Le Puy; Douais, C. (ed.). 1900. Documents pour servir à l'histoire de I'Inquisition dans le Languedoc, 2 vols: ii, 98-103. París: Renouard.

${ }^{56}$ BNP, Doat, xxxiii, f. 73; Puig, C. 1998. "Inquisition et hérésie en Roussillon au XIII siècle". Études Roussillonnaises 16: 46; Soulassol, J.-C. 2005. "Les Alion, le pape et le comte de Foix", en M. Aurell (ed.), Les Cathares devant l'histoire: mélanges offerts á Jean Duvernoy: 382. Cahors.

${ }_{57}$ ADPO, 1B10; Douais. 1900: i, p. 34, n.8; Puig. 1998: 46-7.

${ }^{58}$ BNP, Doat, xxxiii, f. 122v-124; Douais. 1900: i, 34, n. 8; Puig. 1998: 47.

59 ACA, pergamins. Jaume I, n. 910; Ventura, J. 1959-60. "El Catarismo en Cataluña". Boletín de la Real Academia de Buenas Letras de Barcelona 28: 101.

60 Domínguez Sánchez. 2004: 753-4, no. 978; Berger, E. (ed.). 1881-1921. Les Registres d'Innocent IV (1243-54), 4 vols: iii, n. 799. París: Bibliothèque des Ecoles Françaises d'Athènes et de Rome.

${ }^{61}$ BMT, Ms. 609, f. 120v. 
cónsules pidieran medidas contra la entrada de los herejes en la ciudad. ${ }^{62}$ Pero, en septiembre de 1237, el papa aconsejó que la Inquisición no cometiera errores por la condena de inocentes debido a falsos testimonios. ${ }^{63}$ En realidad, los casos en Montpellier fueron muy pocos, e igualmente carecemos de indicios de actividad herética en el Valle de Arán durante el período en el que estuvo bajo el control de la Corona, a partir de $1201 .{ }^{64}$ En Andorra, solamente sabemos de un hereje, Joan, capturado por la Inquisición en 1237, pero esto podría explicarse porque la Iglesia fue obstaculizada en su tarea por un castillo construido a la entrada del valle por el conde Roger IV de Foix, precisamente para proteger la comarca de los hombres del obispo. ${ }^{65}$

En las tierras de reciente conquista, la herejía estuvo más extendida. En 1239, Ramon de Torrelles, obispo de Mallorca, escribió al papa Gregorio IX denunciando a miembros de la clerecía y del laicado que habían atacado físicamente a otros clérigos y a otros religiosos, que habían ayudado a los albigenses contra la Iglesia y que habían vendido a los sarracenos productos que no podían venderles. ${ }^{66}$ Algunos testimonios en presencia de Bernart de Caus, inquisidor en Quercy, sugieren que los herejes tuvieron una presencia regular en Mallorca. Raimonde, la mujer de Bossolens, dijo que había visto muchas veces a los herejes en la casa de su marido en Mallorca y que los había adorado y había comido con ellos. ${ }^{67}$ Durand de Brouille había visto dos herejes en Mallorca y también había comido con ellos en la misma mesa. Durand insistió en que al principio no sabía que eran herejes y en que se enteró más tarde. Su encuentro le costaría peregrinar a Le Puy, a Saint Gilles y a Compostela. ${ }^{68}$ En el reino de Valencia, la Inquisición se estableció en Morella en 1262. Había un número significativo de herejes y algunos de ellos, por ejemplo la familia Calça, poseían una cantidad importante de propiedades y tenían bastante que perder. Muchas tierras y propiedades de los condenados fueron transferidas por el rey a familias más fiables. ${ }^{69}$ Morella, sin embargo, siguió siendo un lugar donde los refugiados heréticos encontraban una buena acogida, incluido el conocido Guilhem Bélibaste en los primeros años del siglo XIV. ${ }^{70}$

En otras tierras de la Corona de Aragón, los herejes eran pocos. Arnau de Godera no encontró ninguno en Barcelona en 1215. ${ }^{71}$ Aunque el conde Hug d'Empúries pudo haber tenido algún hereje en las filas de su ejército cuando atacó las tierras del obispo de Gerona en $1225,{ }^{72}$ no hay menciones de ellos en esa zona.

${ }^{62}$ Auvray, L. (ed.). 1890-1906. Registres de Grégoire IX (1227-41), 4 vols: ii, n. 3527. París: Fontemoing; Devic, 2003: vi, 702.

63 Rouquette, J. y Villemagne, A. (eds.). 1914. Bullaire de l'Église de Maguelone, 4 vols: ii, no. 355. Montpellier: Valat.

${ }^{64}$ Smith. 2010: 116.

65 BNP, Doat, clxx, f. 75; Devic, 2003: viii, 1010-1.

66 Domínguez Sánchez. 2004: 706-7, n. 904.

67 Duvernoy, J. (ed.). 2001. L'Inquisition en Quercy: le registre des pénitences de Pierre Cellan 1241-1242: 180. Castelnaud de la Chapelle.

68 Ibídem: 206.

69 Burns, R. I. (ed.). 1985-2011. Diplomatarium of the Crusader Kingdom of Valencia: the Registered Charters of Its Conqueror, Jaume I, 1257-1276, 4 vols: ii, 357-61, n. 413-416. Princeton: Princeton University Press.

${ }^{70}$ Véase Le Roy Ladurie, E. 1984. Montaillou, Londres: Harmondsworth; Weiss, R. 2001. The Yellow Cross: The Story of the Last Cathars 1290-1329. Londres: Penguin.

${ }^{71}$ BMT, ms. 609, f. 144.

72 Benito i Monclús, P. 2004. “La submissió del comte Hug IV d’Empúries i de la noblesa emporitana a l'Església de Girona (1226-1229): una repercussió de la croada albigesa liderada per 
En Vic, la única acusación de herejía fue contra el obispo Guillem de Tavartet en 1232-1233, pero sólo como parte de un esfuerzo concertado por los canónigos para liberarse del prelado. ${ }^{73}$ La Iglesia de Zaragoza recibió Excommunicamus, la bula seminal de Gregorio IX de febrero de 1231, pero no hay ninguna evidencia de herejía allí. ${ }^{74}$

Fuera de la Corona de Aragón también hubo herejes, por ejemplo, en Palencia, donde los oficiales de Fernando III intervinieron y marcaron a fuego el rostro de los herejes; ${ }^{75}$ en Burgos, donde un ciudadano, Vidal de Arvial, persuadido por el diablo, se había comunicado con ciertos herejes de vez en cuando, había comido con ellos en la misma mesa, había hablado con ellos y, con su cabeza inclinada, se había arrodillado haciéndoles una reverencia; ${ }^{76}$ y en León, donde Lucas de Tuy hizo campaña y escribió un tratado contra los albigenses, aunque aparentemente sin investigar sobre sus creencias. ${ }^{77}$

En la Corona de Aragón, desde luego no es una coincidencia que en las tierras donde el poder regio era más fuerte, la herejía fuera más débil, aunque conviene decir que esto no es del todo así cuándo hablamos de los valdenses, cuyo número parece mayor de lo que han afirmado los historiadores. Los valdenses fueron el objetivo inicial de la legislación real de Alfonso II y Pedro II en 1194 y 1198 respectivamente. ${ }^{78}$ En 1200, en la diócesis de Urgel, cuando Arnau de Puigverd juró por los evangelios ante el obispo Bernat de Urgel que no apoyaría a los herejes a sabiendas, también juró que no apoyaría a los inçabatati. ${ }^{79}$ Además, es muy probable que los valdenses fueran los herejes que más preocupaban a la reinaviuda Sancha cuando escribió a Inocencio III desde Sijena, recibiendo en respuesta del papa un ejemplar de la célebre bula Vergentis in senium. ${ }^{80} \mathrm{El}$ converso Durán, antiguo valdense, era casi con seguridad de Huesca, y, de hecho, los Pobres Católicos fueron tan activos en Huesca y Barcelona que los obispos de estas sedes recibieron cartas del papa ordenándoles tratar a los conversos de forma benigna. ${ }^{81}$ Varias cartas fueron dirigidas al arzobispo de Tarragona sobre estos valdenses reconciliados. ${ }^{82}$ Llegaron a ser especialmente activos en la diócesis de Elna. ${ }^{83} \mathrm{El}$

Lluís VIII, rei de França, a Catalunya" en L. Plans i Campderrós (ed.), Esglèsia, societat i poder a les terres de parla catalana: 139-54. Valls: Coordinadora de Centres d'Estudis de Parla Catalana

${ }_{73}$ Mundo, A. 1962. "La renúncia del bisbe de Vic, Guillem de Tavartet (1233) segons la correspondència de Bages i els registres Vaticans". VII Congrés d'història de la Corona d'Aragó, iii: 77-95.

${ }_{75}^{74}$ Domínguez Sánchez. 2004: 178, n. 169.

75 Domínguez Sánchez. 2004: 441-2, n. 539.

${ }^{76}$ Domínguez Sánchez. 2004: 621-2, n. 79.

77 Mariana, J. (ed.) 1612. Lucae Tudensi episcopi. De altera vita fideique controversiis adversus Albigensium errores. Libri III, Ingolstadt: A. Angermarius; Fernández Conde, F. J. 1991. "Un noyau actif d'albigeois en León au commencement du XIlle siècle? Approche critique d'une oeuvre de Luc de Tuy écrite entre 1230 et 1240". Heresis 17: 35-50.

${ }^{78}$ Marqués, J. 1962. 'Alfonso II el Casto y la Seo de Gerona', VII Congrés d'història de la Corona d'Aragó, ii, 218-9; Baraut. 1996-7: 420-2, n. 2.

79 Baraut, C. 1992-1993a. "Els documents, dels anys 1191-1200 de l'Arxiu Capitular de la Seu d'Urgell". Urgellia 11: 69, n. 1904.

${ }^{80}$ Alvira Cabrer, M. y Smith, D. J. 2006/7. "Política antiherética en la Corona de Aragón: una carta inédita de Inocencio III a la reina Sancha (1203)". Acta historica et archaeologica. Mediaevalia 27/28: 65-88.

${ }^{81}$ Mansilla. 1955: 508-9, n. 480. Sobre Durán, Thouzellier, C. 1966. Catharisme et Valdéisme en Languedoc. París: Presses Universitaires de France.

${ }^{82}$ Mansilla. 1955: 413-4, n. 394, 425, n. 406, 460-3, n. 433-4.

${ }^{83}$ Mansilla. 1955: 504-6, n. 474; Thouzellier. 1966: 257-9. 
obispo Berenguer (de Palou) de Barcelona estableció un tribunal inquisitorial contra la depravación herética en su diócesis, muy poco antes de su muerte en 1241, y probablemente esa inquisición iba dirigida contra los valdenses, los cuales figuran como el grupo herético más importante en las instrucciones inquisitoriales de Ramon de Penyafort en 1242, escritas en respuesta a algunas preguntas del sucesor de Berenguer de Palou, Pere d'Albalat. ${ }^{84}$

Aunque no fue nunca inquisidor, está claro que Ramon de Penyafort jugó un papel muy importante en el desarrollo de la Inquisición en las tierras catalanoaragonesas. Cuando los herejes aparecieron, a finales del siglo XII, había pocas directrices sobre la manera de investigar la herejía o sobre el castigo que merecían los herejes si eran culpables. Sobre los herejes, los Usatges de Barcelona sólo declaran que podían confiar en la sinceridad del príncipe, una promesa que en absoluto concuerda con las circunstancias de los últimos años del siglo XII. ${ }^{85} \mathrm{Sin}$ embargo, la legislación de los concilios de Tours y de Letrán III, así como la bula Ad abolendam de Lucio III, debieron ser bien conocidas por los prelados de la provincia de Tarragona poco después de su promulgación. ${ }^{86}$ En los años noventa, los reyes de Aragón Alfonso II y Pedro II -quizás influenciados por el cardenal Gregorio de Sant'Angelo, legado pontificio o quizás por los sacristanes de Barcelona y Vic, Berenguer de Palou y Pere de Tavartet- promulgaron una legislación draconiana contra los herejes. ${ }^{87}$ En 1194, Alfonso los declaró enemigos de la cruz de Cristo y violadores de la religión cristiana, enemigos del rey y de su reino. Como tales, tenían que salir de sus tierras. Los bienes de los herejes y de quienes les ayudaran serían confiscados, y los culpables recibirían el mismo castigo que si hubieran cometido un crimen de alta traición. ${ }^{88}$ En 1198, Pedro II fue más específico y decretó que los cuerpos de los herejes debían ser quemados en la hoguera. ${ }^{89} \mathrm{En}$ realidad, sin embargo, parece que nadie fue exiliado o ejecutado en este período. El propio Pedro II supervisó un debate entre los católicos y los herejes en Carcassonne en $1204 .^{90} \mathrm{Y}$, aparentemente, el concienzudo obispo Bernat de Urgel,

${ }^{84}$ Rius Serra, J. (ed.). 1954. San Raimundo de Penyafort, Diplomatario: 74, n. 64. Barcelona: Universidad de Barcelona, Facultad de Derecho; Valls Taberner, F. (ed.), 1991 [1929]. Diplomatari de Sant Ramon de Penyafort: 13-20, n. 3. Zaragoza: Càtedra d'història del dret i de les institucions. Universidad de Málaga; Baraut. 1996-7: 429-34, n. 8; Douais, C. 1899. "Saint Raymond de Peñafort et les hérétiques. Directoire à l'usage des inquisiteurs aragonais (1242)". Le Moyen Âge 12: 305-25.

${ }^{85}$ Bastardas, J. (ed.). 1984. Usatges de Barcelona: El Codi a mitjan segle XII: 96, n. 60. Barcelona: Fundació Noguera.

${ }^{86}$ (Tours) Mansi, G. D. (ed.) 1759-98. Sacrorum conciliorum nova et amplissima collectio, 31 vols: xxi, 1177-8; Florencia: Zatta; (Letrán III) Alberigo, G. et al. (eds.). 1991. Conciliorum Oecumenicorum Decreta: 224-5. Bologna: Edizione Dehoniane Bologna. ('Ad abolendam') Friedberg, E. (ed.). 1879-81. Corpus luris Canonici. 2 vols: ii, 780-2. Leipzig: ex officina Bernhardi Tauchnitz; Smith. 2010: 171-5.

${ }^{87}$ Marqués. 1962: ii, 218-9; Baraut, 1996-7: 419-22, n. 1-2; Weiss, S. 1995. Die urkunden der päpstlichen legaten von Leo IX. bis Coelestin III (1049-1198): 300-8. Colonia: Böhlau; Smith. 2010: 175-6.

${ }^{88}$ Marqués. 1962: ii, 218-9; Baraut, 1996-7: 419-20, n. 1.

${ }^{89}$ Baraut, 1996-7: 420-2.

90 Villemagne, A. (ed.). 1914. Bullaire du bienheureux Pierre de Castelnau, martyr de la foi (16 février 1208): 107-9, n. 29. Montpellier: Imprimerie de La Manufacture de la charité. Alvira Cabrer, M (ed.). 2010. Pedro el Católico, Rey de Aragón y Conde de Barcelona (1196-1213). Documentos, Testimonios y Memoria Histórica. 6 vols. ii, n. 438. Zaragoza: "Fernando el Católico" (CSIC). 
de acuerdo con la bula Ad abolendam, llevó a cabo una visita episcopal de su diócesis en 1200 para investigar la herejía. ${ }^{91}$ Pero incluso después del IV Concilio de Letrán, donde gran parte de la legislación era de una relevancia inmediata para las recientes inquisiciones en Cataluña y Aragón, toda acción contra la herejía dependió de la Corona, como en las cortes de Vilafranca de 1218 y de Tortosa de 1225 , donde los herejes manifiestos, sus seguidores y quienes les favorecieron fueron colocados fuera de la paz y la tregua. ${ }^{92}$ Además, en abril de 1226, Jaime I, en respuesta al rey de Francia y al cardenal Romano, promulgó un edicto advirtiendo que quienes trataran con los herejes sufrirían la cólera regia. ${ }^{93}$ Por supuesto, aquí debemos recordar que los dominicos, que jugaron un papel sustancial en la lucha contra la herejía, no llegarían a la Península hasta 1217 y que sólo establecerían una casa en Barcelona casi cinco años más tarde. ${ }^{94}$

La situación cambió con la bula de Gregorio IX Declinante iam mundi, enviada en 1231 al arzobispo Aspàreg de Tarragona y sus sufragáneos, que puso el control de las inquisiciones contra herejía en manos de los obispos y los dominicos. Los culpables de herejía debían sufrir los castigos precisados en los Estatutos de Toulouse (1229). ${ }^{95}$ Las cortes de Tarragona, en febrero de 1234 , concedieron el poder de juzgar en asuntos de herejía a los obispos y otras autoridades competentes, y se insistió en que era deber del obispo y de los hombres que actuaban en nombre de los obispos interrogar, calificar y reconciliar a los herejes, relegando al poder secular a un papel secundario. ${ }^{96}$ Fue ahora, en respuesta a las dudas sobre diversos asuntos suscitadas por la forma de actuar de las inquisiciones, cuando Ramon de Penyafort apareció en escena y dio a la inquisición catalano-aragonesa su forma distintiva. Sobre el asunto de la herejía, Ramon era más un halcón que una paloma. Afirmó que los herejes recalcitrantes, así como los clérigos y los laicos negligentes que permitieran florecer la herejía, sufrirían castigos graves. Además, en su Summa de Paenitentia, subrayó que incluso el papa o un emperador podían ser depuestos a causa de la herejía. ${ }^{97}$ Pero su condición de gran abogado, su profundo sentido de la justicia y la equidad, junto con su compasión como dominico, le permitieron esquivar los excesos que se dieron en otros lugares en los años de formación de la Inquisición. ${ }^{98}$ La celebre Nota Raimundi insistió en que las cárceles no podían ser tan duras que causaran la muerte. Por el contrario, debían animar a iniciar una nueva vida, porque el propósito del castigo era corregir la vida de un hombre. ${ }^{99}$ Cuando contestó a las preguntas

${ }^{91}$ Baraut. 1992-3a: 69, n. 1904.

92 Cortes de los Antiguos Reinos de Aragón y de Valencia y Principado de Cataluña (10641327). Cortes de Cataluña. 1896: i, 99, 108. Madrid: Real Academia de Historia.

${ }^{93}$ Devic. 2003: viii, 830-1; Huici-Miranda. 1976-82: i, 162, n. 80.

94 Mamachi, T. 1756. Annales Ordinis Praedicatorum: i, 411, n.13. Roma: Palladis; Valls i Taberner. 1991: 80; Vicaire, M.-H. 1957. Histoire de Saint Dominique, 2 vols: ii, 129, n. 113, 236, n. 123, 309, n. 27. París: Les Editions du Cerf.

${ }^{95}$ Domínguez Sánchez. 2004: 178, n. 169

96 Baraut. 1996-7: 423-5, n. 4. Jiménez-Sanchez. 2008: 329.

97 Ochoa, X. y Diez, A. (eds.) 1976. Raimundus de Pennaforte, Summa de Paenitentia: Lib. 1, tit. V, 2, 318. Roma: Commentarium pro Religiosis.

98 Sobre Ramon y la inquisición, Douais. 1899: 305-22; Galmés, Lorenzo. 2004. "San Ramon de Penyafort y la inquisición en la Alta Catalunya", en Praedicatores Inquisitores. The Dominicans and the Mediaeval inquisition: Acts of the First International Seminar on the Dominicans and the Inquisition. 85-104. Roma: Istituto storico domenicano; Grau Torras. 2012: 280-90.

${ }^{99}$ Rius Serra. 1954: 30, n. 20. 
del desgraciado obispo Ponç de Urgel, Ramon aconsejó que aunque la enormidad del crimen de herejía no podía quedar sin castigo, el verdadero penitente no debía sufrir 'el lazo corredizo de la desesperación' a causa de un exceso de rigor. ${ }^{100}$ La legislación del concilio de Tarragona de 1242 (obra seguramente de Ramon) no solamente desarrolló una clasificación de herejes de una complejidad extraordinaria, sino que también defendió la idea de que todo hereje podía ser reconciliado. ${ }^{101}$

Es muy posible que, en los primeros años de la Inquisición, los inquisidores corrieran más peligro de muerte que los herejes, como pone de manifiesto el trágico final de los dominicos de Urgel Ponç de Planella y Bernat de Travesseres -uno envenenado, el otro despedazado-. ${ }^{102}$ Pero esta situación cambió al terminar la guerra de Jaime I en el reino de Valencia contra el rebelde musulmán al-Azraq. El rey asumió entonces un papel más importante en el apoyo de los tribunales inquisitoriales. Jaime dio mucha ayuda financiera para construir la casa de los dominicos en Lérida, al mismo tiempo que se constituía allí un nuevo Tribunal de la Inquisición. ${ }^{103} \mathrm{Y}$ aunque su entusiasmo sin duda refleja su devoción religiosa, con Jaime siempre cabe sospechar oportunidades económicas y políticas. La amnistía concedida a los herejes de Lérida terminó en recompensas financieras para el rey, en forma de 2.000 morabetinis alfonsinis. ${ }^{104}$ Después de la condena póstuma como hereje de Ponç de Vernet en 1260, su desgraciado hijo y tocayo vio agotadas todas sus tentativas de encontrar el dinero con el que satisfacer las demandas del rey y recuperar sus tierras. ${ }^{105}$ Poco después, en 1262, las posesiones de aquellos condenados como herejes en Montsant y Prades fueron dadas a personas en que el rey confiaba. ${ }^{106}$ Asimismo, en la región de Morella, el Jaime concedió una granja, las viñas y los campos de los herejes condenados a súbditos leales a la Corona. ${ }^{107}$ Las inquisiciones se convirtieron gradualmente en un instrumento de la monarquía, como demuestran los conocidos casos de Arnau y Ermenssenda de Castellbò. Aunque no hay ninguna duda de que eran herejes, sólo fueron condenados como tales en 1269, cuando su culpabilidad fue utilizada por el rey como una excusa para atacar a su descendiente, Roger Bernat de Foix, durante la amarga guerra que Jaime libró contra el conde. ${ }^{108}$ Durante el proceso, el rey cedió a Roger Bernat, a

${ }^{100}$ Rius Serra. 1954: 51, n. 40.

101 Rius Serra. 1954: 74, n. 64; Valls Taberner. 1991: 13-20, n. 3; Baraut. 1996-7: 429-34, n. 8; Errera, A. 2002. "Il Directorium Inquisitoriale di San Raimundo", en C. Longo (ed.) Magister Raimundus: Atti del Convegno per il IV Centenario della canonizzazione di San Raimondo de Penyafort. 165-91. Roma: Institutum Historicum Fratrum Praedicatorum.

102 Kaeppeli, T. (ed.). 1949. Étienne de Salagnac y Bernard Gui, De quatuor in quibus deus praedicatorum ordinem insignivit: 24-5, 161. Roma: Istituto storico domenicano di S. Sabina; Balme, F. y Paban, C. (eds.). 1901. Raymundiana seu documenta quae pertinent ad. S. Raymundi de Pennaforti. Vitam et Scripta, 2 vols: i, 24. Roma: In Domo Generalitia; Reichert, B. M. (ed.) 1896. Gerard de Frachet, Vitae Fratrum ordinis praedicatorum: 301-2. Louvain: Charpentier; Diago, F. 1599. Historia de la Provincia de Aragón de la Orden de Predicadores; 8-9. Barcelona: Sebastian de Cormellas en Sancta Catherina martyr.

103 Huici Miranda. 1976-82: iii, 241, n. 759, 243, n. 762.

${ }^{104}$ Huici Miranda. 1976-82: iii, 243, n. 762.

105 Alart, B. (ed.). 1874. Privilèges et titres de la ville de Perpignan: 232, n. 1-2. Perpignan: Latrobe.

${ }^{106}$ AHN, n. 1234b, f. 140v; Huici Miranda. 1976-82: iv, 321-2, 354-5, n. 1248-9, 1287-8.

107 Burns. 1985-2011: ii, 357-61, n. 413-416.

108 Baraut. 1994-5: 521-3, n. 16-17; Soldevila, F. 1995. Pere el Gran, 2 vols: i, 91. Barcelona: Institut d'Estudis Catalans; Bruguera. 1991: c. 474. 
cambio del pago de 45.000 sueldos barceloneses, los derechos que tenía en el vizcondado de Castellbò y otras posesiones que el conde poseía como descendiente de Arnau y Ermessenda, acusados de depravación herética. Jaime decretó que, aunque fueran condenados como culpables del crimen de herejía por la Iglesia, por su liberalidad y su gracia especial, garantizaría todas las tierras que Roger Bernat poseía de sus antepasados criminales. ${ }^{109}$ La humillación fue, pues, calculada.

Los recursos limitados de la Corona, tanto financieros como militares, que eran problemas importantes de la expansión mediterránea, influyeron también en el desarrollo de la Inquisición. La monarquía de Jaime I había alejado a la Corona de Aragón de un conflicto con el Papado y Francia (juna política que, por supuesto, el hijo de Jaime no seguiría!) ${ }^{110}$. La presencia o la ausencia de la autoridad regia jugó igualmente un papel enorme en la determinación de la presencia o de la ausencia de herejes en sus tierras. Pero en el proceso de desarrollo de la Inquisición, el grado de la influencia de la monarquía fue, en última instancia, poco pronunciado. En un principio, los reyes de Aragón publicaron algunas leyes duras contra la herejía, pero el Papado, conjuntamente con los obispos locales y los dominicos, desarrolló procedimientos y mecanismos antiheréticos que dejaban al rey y a otros señores seculares en una posición subordinada. La presencia de la figura intelectual de Ramon de Penyafort impidió que se repitieran muchos de los excesos vistos en otras regiones y que muchos de los problemas de las inquisiciones fueran resueltos antes en la Corona de Aragón que en otras partes. Sin embargo, después de las conquistas de Mallorca y de Valencia, la influencia creciente del poder regio en la represión de la herejía significó que, en ocasiones, las inquisiciones eclesiásticas pudieran quedar al servicio de los objetivos de la monarquía.

\section{FUENTES Y BIBLIOGRAFÍA}

Archivo Histórico Nacional, Madrid (AHN)

Archives départementales des Pyrénées-Orientales, Perpiñán (ADPO)

Arxiu de Bagà $(A B)$

Archivo de la Corona de Aragón/Arxiu de la Corona d'Aragó (ACA)

Arxiu Capitular d'Urgell (ACU)

Bibliothèque Municipale, Toulouse (BMT)

Bibliothèque nationale, París (BNP)

Adroer, A. y Catalá, P. 1986. Càtars i Catarisme a Catalunya. Barcelona: Rafael Dalmau.

Alart, B. (ed.). 1874. Privilèges et titres de la ville de Perpignan. Perpiñán: Latrobe. Alberigo, G. et al. (eds.). 1991. Conciliorum Oecumenicorum Decreta. Bolonia: Edizione Dehoniane Bologna.

109 Baraut, C. (ed.). 1988-90. Cartulari de la vall d'Andorra. Segles IX-XIII. 2 vols: ii, 294-5, n. 121. Andorra: Conselleria d'Educació i Cultura del Govern d'Andorra; Baraut. 1994-5: 520-1, n. 15.

\footnotetext{
${ }^{110}$ Cingolani. 2010.
} 
Alvira Cabrer, M. 2002. El Jueves de Muret. Barcelona: Universitat de Barcelona.

Alvira Cabrer, M. 2008. Muret 1213. La batalla decisiva de la Cruzada contra los Cátaros. Madrid: Ariel.

Alvira Cabrer, M. (ed.). 2010. Pedro el Católico, Rey de Aragón y Conde de Barcelona (1196-1213). Documentos, Testimonios y Memoria Histórica. 6 vols. Zaragoza: "Fernando el Católico" (CSIC).

Alvira Cabrer, M., Macé, L. y Smith, D.J. 2009. "Le temps de la Grande Couronne d'Aragon du roi Pierre le Catholique. À propos de deux documents relatifs à l'abbaye de Poblet (février et septembre 1213)". Annales du Midi 265: 5-22.

Alvira Cabrer, M. y Smith, D. J. 2006/7. "Política antiherética en la Corona de Aragón: una carta inédita de Inocencio III a la reina Sancha (1203)". Acta historica et archaeologica. Mediaevalia 27/28: 65-88.

Baldwin, J. 1992. The Government of Philip Augustus. Berkeley, University of California Press.

Balme, F. y Paban, C. (eds.). 1901. Raymundiana seu documenta quae pertinent ad. S. Raymundi de Pennaforti. Vitam et Scripta, 2 vols. Roma: In Domo Generalitia.

Baraut, C. (ed.). 1988-90. Cartulari de la vall d'Andorra. Segles IX-XIII. 2 vols. Andorra: Conselleria d'Educació i Cultura del Govern d'Andorra.

Baraut, C. 1992-1993a. "Els documents, dels anys 1191-1200 de l'Arxiu Capitular de la Seu d'Urgell". Urgellia 11: 7-160.

Baraut, C. 1992-1993b. "L'evolució política de la senyoria d'Andorra des dels orígens fins als Pariatges (segles IX-XIII)". Urgellia 11: 225-99.

Baraut, C. 1994-1995. "La presencia i la repressió del catarisme al bisbat d'Urgell (segles XII-XIII)". Urgellia 12: 487-524.

Baraut, C. 1996-1997. "Els inicis de la inquisició a Catalunya i les seves actuacions al bisbat d'Urgell (segles XII-XIII)". Urgellia 13: 407-438.

Bartrina, E. 1999. Els Càtars al Berguedà. Bagà: Associació Medieval de Bagà.

Bastardas, J. (ed.). 1984. Usatges de Barcelona: El Codi a mitjan segle XII. Barcelona: Fundació Noguera.

Benito i Monclús, P. 2004. "La submissió del comte Hug IV d’Empúries i de la noblesa emporitana a l'Església de Girona (1226-1229): una repercussió de la croada albigesa liderada per Lluís VIII, rei de França, a Catalunya" en L. Plans i Campderrós (ed.), Esglèsia, societat i poder a les terres de parla catalana: 139-54. Valls: Coordinadora de Centres d'Estudis de Parla Catalana.

Benito i Monclús, P. 2009. "L'expansió territorial ultrapirinenca de Barcelona i de la Corona d'Aragó: guerra, política i diplomàcia (1067-1213)", en Ferrer i Mallol, M.T. y Riu i Riu, M. (dirs.), Tractats $i$ negociacions diplomàtiques de Catalunya $i$ de la Corona catalanoaragonesa a l'edat mitjana. Vol. I.1: Tractats $i$ negociacions diplomàtiques amb Occitània, França $i$ els estats italians, 1067-1213: 13-150. Barcelona, Institut d'Estudis Catalans (Memòries de la Secció Històrico-Arqueològica, 83).

Berger, E. (ed.). 1881-1921. Les Registres d'Innocent IV (1243-54), 4 vols. París: Bibliothèque des Ecoles Françaises d'Athènes et de Rome.

Bisson, T. 1984. Fiscal Accounts of Catalonia under the Early Count-Kings (11511213), 2 vols. Berkeley: University of California Press. 
Bisson, T. 1989. "The Finances of the Young King Jaime I (1213-28)" en Idem, Medieval France and her Pyrenean Neighbours: Studies in Early Institutional History: 351-92 London: Hambledon Press.

Bruguera, J. (ed.). 1991. Jaume I. Llibre dels Fets, 2 vols. Barcelona: Editorial Barcino.

Burns, R. I. 1987-8. "The Loss of Provence. King Jaime's raid to kidnap its heiress (1245): Documenting a legend". XII Congrés d'història de la Corona d'Aragó, iii, 195-231.

Burns, R. I. 1988. “A Lost Crusade: Unpublished Bulls of Innocent IV on al-Azraq's revolt in Thirteenth century Spain". Catholic Historical Review 74: 440-9.

Burns, R. I. (ed.). 1985-2011. Diplomatarium of the Crusader Kingdom of Valencia: the registered charters of its conqueror, Jaume I, 1257-1276, 4 vols. Princeton: Princeton University Press.

Cateura, P. 2008. “Jaume I: conquesta i organització del regne de Mallorca”, en G. Colón y T. Martínez Romero (eds.), El rei Jaume I: Fets, actes i paraules: 3351. Barcelona: Publicacions de l'Abadia de Montserrat.

Cazenave, A. 1972. "Les Cathares en Catalogne et Sabarthès d'après les registres d'Inquisition: la hiérarchie Cathare en Sabarthès après Montsegur". Bulletin philologique et historique: 387-436.

Cingolani, S. 2007. La Memòria dels Reis: Les quatre grans cròniques. Barcelona: Editorial Base.

Cingolani, S. 2010. Pere el Gran: Vida, Actes i Paraula. Barcelona: Editorial Base.

Claramunt, S. 2009. "La nobleza en Cataluña durante el reinado de Jaime I", en E. Sarasa (ed.), La sociedad en Aragón y Cataluña en el reinado de Jaime I (1213-1276): 199-229. Zaragoza, CSIC.

Cortes de los Antiguos Reinos de Aragón y de Valencia y Principado de Cataluña (1064-1327). Cortes de Cataluña. 1896. Madrid: Real Academia de Historia.

Devic, C. y Vaissète, J. (eds.). 2003 [1730-45]. Histoire générale de Languedoc. 16 vols. Toulouse: Bibliothèque des introuvables.

Diago, F. 1599. Historia de la Provincia de Aragón de la Orden de Predicadores. Barcelona: Sebastian de Cormellas en Sancta Catherina martyr.

Domínguez Sánchez, S. (ed.). 2004. Documentos de Gregorio IX (1227-1241) referentes a España. León: Universidad de León.

Dossat, Y. 1961. "Les deux serments de fidelité des consuls de Toulouse en septembre 1271". Bulletin philologique et historique: 703-11.

Dossat, Y. 1966. Saisimentum Comitatus Tholosani. París: Bibliothèque nationale.

Douais, C. 1899. "Saint Raymond de Peñafort et les héretiques. Directoire à l'usage des inquisiteurs aragonais (1242)". Le Moyen Âge 12: 305-25.

Douais, C. (ed.). 1900. Documents pour servir à l'histoire de l'Inquisition dans le Languedoc, 2 vols. París: Renouard.

Durán Gudiol, A. (ed.). 1965-7. Colección diplomática de la catedral de Huesca, 2 vols. Zaragoza: CSIC.

Duvernoy, J. (ed.). 1996. Guillaume de Puylaurens, Chronique 1145-1175, Toulouse: Le Pérégrinateur.

Duvernoy, J. (ed.). 2001. L'Inquisition en Quercy: le registre des pénitences de Pierre Cellan 1241-1242. Castelnaud de la Chapelle: L'Hydre.

Engels, O., 1962. "Der Vertrag von Corbeil (1258)". Gesammelte Aufsätze zur Kulturgeschichte Spaniens 19: 114-46. 
Errera, A. 2002. "Il Directorium Inquisitoriale di San Raimundo", en C. Longo (ed.) Magister Raimundus: Atti del Convegno per il IV Centenario della canonizzazione di San Raimondo de Penyafort. 165-91. Roma: Institutum Historicum Fratrum Praedicatorum.

Fernández Conde, F. J. 1991. "Un noyau actif d'albigeois en León au commencement du XIIle siècle? Approche critique d'une oeuvre de Luc de Tuy écrite entre 1230 et 1240". Heresis 17: 35-50.

Fondevilla, F. 1908. "La nobleza catalano-aragonesa capitaneada por Ferrán Sánxez de Castro" I Congrés d'història de la Corona d'Aragó, ii: 1061-1168.

Fort i Cogul, E. 1973. Catalunya i la Inquisició. Barcelona: Editorial Aedos.

Friedberg, E. (ed.). 1879-81. Corpus luris Canonici. 2 vols. Leipzig: ex officina Bernhardi Tauchnitz.

Galmés, Lorenzo. 2004. "San Ramon de Penyafort y la inquisición en la Alta Catalunya", en Praedicatores Inquisitores. The Dominicans and the mediaeval inquisition: Acts of the First International Seminar on the Dominicans and the Inquisition: 85-104. Roma: Istituto storico domenicano.

Gascón Chopo, C. 2003. Crisis social, espiritualidad y herejía en la diócesis de Urgel (siglos XII-XIII): Los orígenes y la difusión de la herejía cátara en la antigua diócesis de Urgel, Ph.D, Facultad de Geografía e Historia, Universidad Nacional de Educación a Distancia.

Gonzalvo i Bou, G. (ed.). 1994. Les Constitucions de Pau i Treva de Catalunya: segles XI-XIII. Barcelona: Generalitat de Catalunya, Departament de Justícia.

Gort, E. 2006. Occitans i Càtars a Montsant i muntanyes de Prades (Segles XIIXIV). Albarca: Migdia.

Grau Torras, S. 2012. Cátaros e Inquisición. Madrid: Cátedra.

Guébin, P. y Lyons, E., (eds.). 1926-39. Petrum Vallium Sernaii monachi Hystoria Albigensis. París: Champion

Guinot, E. 1999. Els fundadors del regne de València, 2 vols. Valencia: Climent.

Hageneder, O. y Haidacher, A. (eds.). 1964. Die Register Innocenz' III, 1. Pontifikatsjahr. Colonia: Böhlau.

Hamilton, B. 1978. "The Cathar council of Saint-Félix reconsidered". Archivum Fratrum Praedicatorum 48: 23-53.

Hillgarth, J. 1975. The Problem of a Catalan Mediterranean Empire, 1229-1327. Londres: Longman.

Huici Miranda, A. y Cabanes Pecourt, M. (eds.). 1976-82. Documentos de Jaime I de Aragón. 5 vols. Valencia-Zaragoza: Anúbar.

Jiménez-Sanchez, P. 2008. Les catharismes: Modèles dissidents du christianisme médiéval (XIle-XIIle siècles). Rennes: Presses Universitaires de Rennes.

Le Roy Ladurie, E. 1984. Montaillou, Londres: Harmondsworth.

Kaeppeli, T. (ed.). 1949. Étienne de Salagnac y Bernard Gui, De quatuor in quibus Deus praedicatorum ordinem insignivit. Roma: Istituto storico domenicano di S. Sabina.

Mamachi, T. 1756. Annales Ordinis Praedicatorum, Roma: Palladis.

Mansi, G. D. (ed.) 1759-98. Sacrorum conciliorum nova et amplissima collectio, 31 vols, Florencia: Zatta.

Mansilla, D. (ed.) 1955. La documentación pontificia hasta Inocencio III (965-1216). Roma: Instituto Español de Estudios Eclesiásticos.

Mansilla, D. (ed.) 1965. La documentación pontificia de Honorio III (1216-1227). Roma. Instituto Español de Estudios Eclesiásticos. 
Mariana, J. (ed.) 1612. Lucae Tudensi episcopi. De altera vita fideique controversiis adversus Albigensium errores. Libri III, Ingolstadt: A. Angermarius.

Marquès, J. (ed.) 1984. Pergamins de la Mitra (891-1687), Arxiu diocesà de Girona. Gerona: Institut d'Estudis Gironins.

Marqués, J. 1962. "Alfonso II el Casto y la Seo de Gerona", VII Congrés d'història de la Corona d'Aragó, ii: 207-22.

Molinier, C. (ed.). 1880. Guilhem Pelhisso, Chronique. Le Puy.

Mundo, A. 1962. "La renúncia del bisbe de Vic Guillem de Tavartet (1233) segons la correspondència de Bages i els registres Vaticans". VII Congrés d'història de la Corona d'Aragó, iii: 77-95.

Nicolau y d'Olwer, L. 1908. "Jaume I y los trovadors provensals". I Congrés d'història de la Corona d'Aragó, i: 389-407.

Ochoa, X. y Diez, A. (eds.) 1976. Raimundus de Pennaforte, Summa de Paenitentia. Roma: Commentarium pro Religiosis.

Pecout, T. 2004. Raymond Bérenguer V: L'invention de la Provence. París: Perrin.

Puig, C. 1998. "Inquisition et hérésie en Roussillon au XIII siècle". Études Roussillonnaises 16: 43-50.

Pujol, J. M. 2008. "El programa narratiu del Llibre del Rei En Jaume", en G. Colón y T. Martínez Romero (eds.), El rei Jaume I: Fets, actes i paraules. 257-86. Barcelona: Publicacions de l'Abadia de Montserrat.

Pujol, P. 1984. Obra Completa. Andorra: Editorial Andorra.

Quintano Prieto, A. (ed.). 1987. La documentación pontificia de Inocencio IV (124354). Roma: Instituto Español de Historia Eclesiástica.

Reichert, B. M. (ed.) 1896. Gerard de Frachet, Vitae Fratrum ordinis praedicatorum. Louvain: Charpentier.

Rius Serra, J. (ed.). 1954. San Raimundo de Penyafort, Diplomatario. Barcelona: Universidad de Barcelona, Facultad de Derecho.

Rouquette, J. y Villemagne, A. (eds.). 1914. Bullaire de l'Église de Maguelone, 4 vols, Montpellier: Valat.

Smith, D. J. 2004. Innocent III and the Crown of Aragon: the limits of papal authority. Aldershot: Ashgate.

Smith, D. J. 2010. Crusade, heresy and inquisition in the lands of the Crown of Aragon (c. 1167-1276). Leiden: Brill Academic Press.

Soldevila, F. 1995. Pere el Gran, 2 vols. Barcelona: Institut d'Estudis Catalans.

Soulassol, J.-C. 2005. "Les Alion, le pape et le comte de Foix", en M. Aurell (ed.), Les Cathares devant l'histoire: mélanges offerts á Jean Duvernoy. Cahors: L'Hydre.

Teulet, A. (ed.)1863-1909. Layettes du trésor des Chartes, 5 vols. París: Plon.

Thouzellier, C. 1966. Catharisme et Valdéisme en Languedoc. París: Presses Universitaires de France.

Torró, J. 2008. "Jaume I i la formació del Regne de València. Una perspectiva general”, en G. Colón y T. Martínez Romero (eds.), El rei Jaume I: Fets, actes i paraules 13-32. Barcelona: Publicacions de l'Abadia de Montserrat.

Utrilla Utrilla, J. 2009. "La nobleza aragonesa y el Estado en el siglo XIII: composición, jerarquización y comportamientos políticos", en E. Sarasa (ed.), La sociedad en Aragón y Cataluña en el reinado de Jaime I (1213-1276): 199-229. Zaragoza: CSIC. 
Valls Taberner, F. (ed.), 1991 [1929]. Diplomatari de Sant Ramon de Penyafort. Zaragoza: Càtedra d'Història del Dret i de les Institucions. Universidad de Málaga.

Ventura, J. 1959-60. "El Catarismo en Cataluña". Boletín de la Real Academia de Buenas Letras de Barcelona 28: 75-168.

Ventura, J. 1961-2. "La Valdesía de Cataluña". Boletín de la Real Academia de Buenas Letras de Barcelona 29: 275-317.

Ventura, J. 1963. Els heretges catalans. Barcelona: Selecta.

Vicaire, M.-H. 1957. Histoire de Saint Dominique, 2 vols. París: Les Editions du Cerf.

Villemagne, A. (ed.). 1914. Bullaire du bienheureux Pierre de Castelnau, martyr de la foi (16 février 1208). Montpellier: Imprimerie de La Manufacture de la Charité.

Vincke, J. 1941. Zur Vorgeschichte der Spanischen Inquisition: Die Inquisition in Aragon, Katalonien, Mallorca und Valencia während des 13. und 14. Jahrhunderts. Bonn: Hanstein.

Wakefield, W. 1970. "The Family of Niort in the Albigensian Crusade and before the Inquisition", Names: Journal of the American Name Society, 18: 97-117, 286-303.

Weiss, R. 2001. The Yellow Cross: The Story of the Last Cathars 1290-1329. Londres: Penguin.

Weiss, S. 1995. Die urkunden der päpstlichen legaten von Leo IX. bis Coelestin III (1049-1198). Colonia: Böhlau.

Zerner, M. (ed.). 2001. L'histoire du Catharisme en discussion: Le 'Concile' de Saint-Félix (1167). Nice: Université de Nice.

Zurita, J. 1967-1986 [1562-80]. Anales de la Corona de Aragón, 8 vols. Zaragoza: Institución "Fernando el Católico", CSIC. 